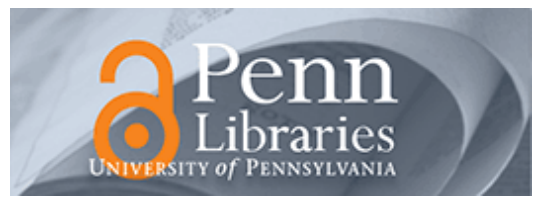

University of Pennsylvania

ScholarlyCommons

Management Papers

Wharton Faculty Research

$3-2014$

\title{
Make, Buy, Organize: The Interplay between Research, External Knowledge, and Firm Structure
}

Ashish Arora

Sharon Belenzon

Luis A. Rios

University of Pennsylvania

Follow this and additional works at: https://repository.upenn.edu/mgmt_papers

Part of the Business Administration, Management, and Operations Commons, Business Analytics Commons, Business and Corporate Communications Commons, Business Law, Public Responsibility, and Ethics Commons, Management Information Systems Commons, Management Sciences and Quantitative Methods Commons, Operations and Supply Chain Management Commons, Organizational Behavior and Theory Commons, and the Strategic Management Policy Commons

\section{Recommended Citation}

Arora, A., Belenzon, S., \& Rios, L. A. (2014). Make, Buy, Organize: The Interplay between Research, External Knowledge, and Firm Structure. Strategic Management Journal, 35 (3), 317-337. http://dx.doi.org/ 10.1002/smj.2098

This paper is posted at ScholarlyCommons. https://repository.upenn.edu/mgmt_papers/334

For more information, please contact repository@pobox.upenn.edu. 


\title{
Make, Buy, Organize: The Interplay between Research, External Knowledge, and Firm Structure
}

\author{
Abstract \\ We bridge current streams of innovation research to explore the interplay between R\&D, external \\ knowledge, and organizational structure-three elements of a firm's innovation strategy which we argue \\ should logically be studied together. Using within-firm patent assignment patterns, we develop a novel \\ measure of structure for a large sample of American firms. We find that centralized firms invest more in \\ research and patent more per R\&D dollar than decentralized firms. Both types access technology via \\ mergers and acquisitions, but their acquisitions differ in terms of frequency, size, and integration. \\ Consistent with our framework, their sources of value creation differ: while centralized firms derive more \\ value from internal R\&D, decentralized firms rely more on external knowledge. We discuss how these \\ findings should stimulate more integrative work on theories of innovation.

\section{Keywords} \\ decentralization, organizational structure, mergers and acquisitions, patents, R\&D, market value

\section{Disciplines} \\ Business Administration, Management, and Operations | Business Analytics | Business and Corporate \\ Communications | Business Law, Public Responsibility, and Ethics | Management Information Systems | \\ Management Sciences and Quantitative Methods | Operations and Supply Chain Management | \\ Organizational Behavior and Theory I Strategic Management Policy
}




\title{
Make, Buy, Organize: The Interplay Between Research, External Knowledge, and Firm Structure*
}

\author{
Ashish Arora $^{\dagger} \quad$ Sharon Belenzon ${ }^{\ddagger} \quad$ Luis A. Rios ${ }^{\S}$
}

December 11, 2012

\begin{abstract}
We bridge current streams of innovation research to explore the interplay between R\&D, external knowledge, and organizational structure-three elements of a firm's innovation strategy which we argue should logically be studied together. Using within-firm patent assignment patterns, we develop a novel measure of structure for a large sample of American firms. We find that centralized firms invest more in research and patent more per R\&D dollar than decentralized firms. Both types access technology via mergers and acquisitions, but their acquisitions differ in terms of frequency, size, and integration. Consistent with our framework, their sources of value creation differ: while centralized firms derive more value from internal $\mathrm{R} \& \mathrm{D}$, decentralized firms rely more on external knowledge. We discuss how these findings should stimulate more integrative work on theories of innovation.
\end{abstract}

Keywords: decentralization, organizational structure, mergers and acquisitions, patents, $\mathrm{R} \& \mathrm{D}$, market value

JEL Classification: D23 D83 L22

\section{Introduction}

How do firms allocate resources between R\&D and external technology in order to maximize value and drive growth? And in turn, do their ensuing growth trajectories themselves shape such future resource allocation? Over the past three decades, the field of innovation strategy

*All authors contributed equally and are listed in alphabetical order.

${ }^{\dagger}$ Duke University, Fuqua School of Business, 100 Fuqua Drive, Durham, NC 27708, U.S.A. E-mail: ashish.arora@duke.edu

${ }^{\ddagger}$ Duke University, Fuqua School of Business, 100 Fuqua Drive, Durham, NC 27708, U.S.A. E-mail: sharon.belenzon@duke.edu

${ }^{\S}$ Corresponding author. Duke University, Fuqua School of Business, 100 Fuqua Drive, Durham, NC 27708, U.S.A. E-mail: luis.rios@duke.edu 
has isolated a set of important dyadic relationships in an effort to understand these interrelated questions. For example, a substantial body of work has advanced our understanding of the relationship between internal R\&D and external knowledge, (e.g. Cohen and Levinthal, 1990; Pisano, 1990; Katz and Allen, 1982). More recently, a small literature on the structure of R\&D has explored how the resource allocation decision is related to the centralization or decentralization of R\&D (e.g. Argyres and Silverman, 2004; Lerner and Wulf, 2007). Separately, work on structural integration and resource reconfiguration has looked at how organizations are shaped by acquisitions and absorption (e.g., Ahuja and Katila, 2001; Puranam, Singh, and Zollo, 2006; Karim and Mitchell, 2000).

Surprisingly, there remains little integration of the aforementioned streams. This lack of synthesis may be due to data constrains, since most work that considers such organizational dynamics tends to rely on small samples (Karim and Mitchell, 2004, and Cohen and Levinthal, 1990 are notable exceptions). Understandably, researchers must often cede the pursuit of a richer understanding of strategic interrelationships in exchange for "analytical precision and theoretical rigor" (Zollo and Singh, 2004). Nonetheless, this lacuna is an important and understudied limitation, since the very word "organization"- from the Greek organon ("tool, instrument, set of rules")- denotes a coherent system or unit where interdependent parts work as one. In fact, a central tenet of organization theory holds that the structures, systems, and processes of a firm should be interdependent and must be mutually supportive and coherent (Drazin and Van de Ven, 1985; Nadler and Tushman, 1997; Rivkin and Siggelkow, 2003; Siggelkow, 2011).

It is the pursuit of this coherence logic that motivates our paper. Using a novel largescale dataset, we explore whether firms demonstrate distinct and coherent combinations of R\&D organizational structure and knowledge-sourcing strategies, as would be expected given the concatenated predictions of these emerging theories of innovation. We propose that firms pursuing a particular approach to innovation (e.g., a strong focus on internal research like IBM or an "acquire and develop" approach like Cisco) also need a well-matched supporting organizational structure (e.g., centralized or decentralized). Empirically, we exploit a sample that includes nearly all patenting public American firms, and develop a new measure of $R \& D$ organizational structure which uses the ratio of patents assigned to affiliates versus corporate parents as a proxy for the decentralization of R\&D. This involves matching 576,052 patents to 1,014 publicly traded American corporations and their 2,768 affiliates. By documenting the types of choices that firms make, we bridge streams of the literature that have previously studied dyadic relationships between internal and external knowledge sourcing, between organizational 
structure and innovation, and between acquisitions and structure.

Our findings extend and clarify prior results. We find evidence that strongly supports the coherence logic. Knowledge sourcing strategies appear to be systematically related to organizational structure. Moreover, the market valuation of these knowledge sourcing strategies strongly correlates with structure. We find confirmatory large-scale evidence that researchoriented firms are significantly more centralized than others, consistent with earlier small-sample findings (Hoskisson, et al. 1993; Kay, 1988; Argyres and Silverman, 2004). But we also find that organizational structure seems to strongly condition the relationship between firms' research focus and their external knowledge acquisition strategy. Though both centralized and decentralized firms acquire external technology, centralized firms do so less frequently and tend to make smaller acquisitions. Moreover, they manage acquisitions differently. Acquisitions by centralized firms frequently undergo full structural integration (Puranam et al., 2006), whereas decentralized firms tend to keep acquisitions as discrete entities.

Importantly, the logic underlying these patterns of choice is reflected in measurable differences in the composition of firms' market value. Whereas centralized firms draw most of their intangible value from internal R\&D stocks, decentralized firms derive relatively more value from externally acquired patents. This finding is especially strong for large firms and firms with higher technological diversity.

Our results imply that a successful innovation strategy requires careful alignment both between internal and external knowledge sourcing, and between the internal/external mix of inputs and organizational structure. The implied coherence, however, does not necessarily imply a particular causal structure. Establishing causality is important, but given the nature of our data, it is beyond the scope of our project. Furthermore, it is just as important to develop a fuller theory of innovation that accounts for the dynamics we highlight in this study. By developing a new empirical measure and systematically exposing the relationships between internal research, external knowledge, and organizational structure among a nearly comprehensive set of firms, we take an important step towards the development of such theory.

\section{Three Pillars of Innovation Strategy}

We draw upon important streams in the innovation literature that have explored dyadic relationships between research, external knowledge and structure. The first explores how the nature of research inside a firm is related to how the activity itself is organized. Firms that invest heavily 
in basic research have been shown to have more centralized $R \& D$, whereas decentralized $R \& D$, managed by business units and divisions, tends to be more applied and incremental (Argyres and Silverman, 2004). This association is theorized to be driven by a fit between function and structure, as research is often managed through a centralized organization to exploit economies of scale and scope. By contrast, development is often managed in business units, closer to where it will be applied (Kay, 1988), arguably because often business unit managers are more likely to favor investments that are closely tied to existing products than large research projects with uncertain payoffs (Hoskisson et al., 1993; Lerner and Wulf, 2007). In sum, we would expect firms that conduct basic research to typically centralize $R \& D$, whereas decentralized firms are less likely to invest in basic research.

Our data allows us to explore whether this relationship, which had previously been shown in small sample studies, also holds in our comprehensive sample. But missing from this literature is an in-depth treatment of the logical consequences that such patterns would imply: If decentralized firms are less likely to conduct basic research themselves, are they also more reliant upon external technology for growth? If so, do decentralized firms approach acquisitions differently? And how much of this difference is the result of organizational structure, and how much the result of differences in the type of R\&D they perform? Though Argyres and Silverman (2004) hint at this issue by exploring how structure conditions a firm's propensity to "build on... innovations developed outside," they conceptualize external search in terms of how much the firm cites external patents, but ignore acquisition of external knowledge via mechanisms that can have feedback effects on structure, like M\&A.

Thus, to probe these questions further, we look to the second literature, which explores how and why firms access external knowledge. Internal research helps firms identify, evaluate, and assimilate external knowledge (Rosenberg, 1979; Cohen and Levinthal, 1990), which often comes via acquisitions (Kogut and Zander, 1993; Fleming, 2001). But while many have interpreted absorptive capacity to imply that internal research should lead to a more efficient acquisition of external knowledge (Arora and Gambardella, 1994), others have argued that investments in internal research may actually bias firms against external knowledge (Katz and Allen, 1982), and that acquisitions may reduce resources and incentives for internal research (Hitt, et al., 1990).

Bridging these streams suggests a complex interplay between internal research, external knowledge, and structure. Here it is useful to consider the insights from a third literature, which has focused on the dynamics of resource recombination. Insofar as decentralization 
is associated with a modular organizational structure (Helfat and Eisenhardt, 2004; Karim, 2006), decentralized firms might find it easier to deal with larger acquisitions. This is because the target can be left to manage itself for the most part, much as other business units are managed. Whether and when the acquired firm is integrated or recombined would depend on the potential synergies with existing units (Karim and Mitchell, 2004), and will likely affect the future autonomy and performance of the target (Puranam, et al., 2006). By contrast, centralized firms will likely have to rapidly integrate a target or allow it to function autonomously. In other words, acquisitions of R\&D-intensive targets can push the firm toward decentralization unless the acquisition is rapidly integrated, which is costly.

For example, Microsoft has a centralized R\&D structure and spent $\$ 9$ billion on R\&D in 2011. Much of this has been in basic research, employing $850 \mathrm{PhDs}$ and leading to key innovations such as Xbox, tablet PC technology, font-resolution technology, and data-mining capabilities. Microsoft has often acquired and built upon external technology, such as Spyglass (the basis for Internet Explorer). Nonetheless, Microsoft has struggled with large acquisitions, such as aQuantive, an online advertising technology firm bought in 2006. Press accounts suggest that a key problem was the difficulty in integrating part of this acquisition into the Online Business Service division. Other parts of aQuantive were ultimately spun off, but the overall deal failed and was reported as a $\$ 6.2$ billion write-off in 2012. In contrast, the more recent acquisition of Skype was handled differently. Skype was left to operate as a standalone subsidiary, effectively moving Microsoft toward a more decentralized structure. This anecdote suggests that even Microsoft's vast technical absorptive capacity was not enough to overcome structural misalignment, and it is the sort of puzzle that motivates us to take this first step at disentangling the role of structure from the role of internal research capabilities in relation to the acquisition of external knowledge.

Clearly, many contingencies may influence the direction in which a firm's strategy and structure develop (Galbraith, 1977). However, a firm will perform well (and survive) if organizational structure, internal research, and knowledge acquisition are aligned to support each other-if they are coherent (Siggelkow, 2011; Teece, et al., 1994; Nadler and Tushman, 1997). Indeed, as a number of notable firm histories have shown, though structure and strategy are not permanent, they seem to coevolve along complementary paths. For instance, DuPont, which relied upon external technologies such as cellophane and rayon before World War I, turned to internal research in the 1930s to generate nylon and acrylics. Along with this shift, it also centralized its R\&D (Hounshell and Smith, 1988). But more recently, DuPont has adopted a more decentralized 
structure, with a number of research-intensive businesses operating as standalone subsidiaries. Tellingly, most of these subsidiaries have come via large acquisitions, such as Pioneer Hi-Bred (a $\$ 10$ Billion seed and agro-chem firm) and Danisco (a $\$ 6$ Bn Danish food ingredients producer). In effect, the new strategy has reinforced the firm's evolution toward decentralization, treating acquisitions as new businesses which bring growth, rather than "key ingredients" to fuel growth via internal recombination (Karim and Williams, 2012; Capron, Dussauge, and Mitchell, 1998).

The evolution of Du Pont, from exploiting external innovations to relying upon internal research to returning to acquisitions is instructive. The changes were sometimes driven by changes in organizational structure, and in other cases, organizational structure adapted to the change (Hounshell and Smith, 1988). What is important for our discussion is that, regardless of the direction of causality, organizational structure and knowledge sourcing seemed to remain coherent. We do not contend that one or the other innovation strategy is better. Rather, these should depend upon the environment and the particularities of the firm itself. As Karim and Mitchell (2004) put it: "The issue is not whether internal development or acquisitions are the most appropriate means of obtaining resources, but how each of the two approaches provides distinct contributions that [create value]." To this we would add that each approach likely requires an organizational structure that is aligned with the approach, and thus increases the likelihood of success.

\section{Sample and Data}

Our paper combines data from several sources: (i) patent-level information from the United States Patent and Trademark Office (USPTO), (ii) ownership structure data from Icarus by Bureau van Djik (BvD), (iii) merger and acquisition data from Thomson Reuters SDC Platinum and Zephyr by BvD, (iv) scientific publications data from Thomson's ISI Web of Knowledge, and $(\mathrm{v})$ accounting information from Compustat. The Online Appendix details the procedures used to construct our various datasets.

We identify the patents held by firms by selecting all patents granted by the USPTO between 1975 and 2007 and assigned to publicly traded US firms or their wholly owned subsidiaries (called affiliates from now on). We match firms to patents by matching assignee names and addresses. The matching is based on comparing the assignee name and address as it appears on the patent document to the name and address of companies in BvD's Icarus database.

At the core of our measure is the fact that patents are often assigned to wholly owned affiliates 
of a parent firm. Because we can identify affiliate-parent relationships from the BvD database, we can distinguish between "centralized" patents assigned to the parent and "decentralized" patents assigned to affiliates. We match a total of 576,052 patents to 1,014 Compustat firms (the "parent" or "headquarter" firms), which themselves own 2,768 affiliates. Of these, 100,951 (or 17.5\%) of our sample patents are decentralized by our measure. To illustrate, Johnson and Johnson (a highly decentralized firm) itself holds only a small fraction of its patents in its own name. The rest are assigned to dozens of wholly owned affiliates.

Ownership data consists of two parts: cross-sectional ownership information from Icarus for 2008, and M\&A data from SDC Platinum and Zephyr. The cross-sectional data shows active affiliates as of 2008, while the M\&A data helps us reconstruct ownership links to affiliates that have dissolved. We exploit the substantial variation in post-merger structural integration (we use the term "absorption" for brevity) to shed light on different acquisition strategies. This is also the basis for a key variable in our analysis, namely the patents owned by a firm that come through an acquisition.

To determine whether an acquired firm is absorbed or kept as an affiliate, we identify all firms that have patents but are no longer active. We then match these firms to the SDC M\&A database to see whether any of these firms have been directly acquired by a sample firm or by one of the affiliates of a sample firm. For example, we identify 121 patents assigned to WebTV Networks, a firm that did not exist as a separate company in 2008. By matching to SDC, we can see that WebTV was purchased in 1997 by Microsoft, then dissolved and absorbed into Microsoft's MSN Networks. This measurement approach works because the original assignee is recorded at the time of the patent grant, allowing us to identify patents by firms (like WebTV) even when the original assignee is dissolved.

\subsection{Patent Assignment as a Proxy for Decentralization}

A major empirical contribution of our paper is the development of a new patent-based measure of decentralization. A virtue of our measure is that it relies on published data and is readily replicable and scalable. Whereas a firm's research focus and external knowledge-sourcing activities can be tracked using patents, R\&D spending or alliances (Arora, Fosfuri, and Gambardella, 2001; Henderson and Cockburn, 1994; Mowery, Oxley, and Silverman, 1996), the internal organization of R\&D is extremely difficult to observe. This fundamentally "within the black box" firm characteristic is by far the most understudied of the three dimensions we discuss here. 
Notable studies in this domain have utilized small samples (Lerner and Wulf, 2007) often acknowledging this limitation and the need for "future empirical research [to] examine the key relationships in larger samples and across longer time periods" (Argyres and Silverman, 2004). As our new measure does precisely this, it promises to open a new window into the internal organization of firms' R\&D function.

We classify individual patents as centralized or decentralized based on whether they are assigned to the parent firm or to the affiliate. Aggregating up to the parent firm level provides share patents assigned, our measure of how centralized or decentralized a firm's patent portfolio is. We also use a discrete version of this measure which classifies a firm as decentralized, hybrid, or decentralized based on the tertile of share patents assigned to which it belongs. For ease of exposition we use "centralized firms" rather than "firms with centralized R\&D organizational structure," since focus is on how research is organized, although we suspect our findings extend to firm structure more broadly. Patent assignment as a measure of decentralization has three important advantages: it is based on observed behavior, it is useful for large samples, and it is replicable.

Patent assignments here have no ownership implications because our American headquarters fully own their affiliates and thus maintain ultimate rights, regardless of who manages the patents. However, we interpret patent assignment as a proxy for the delegation of authority or autonomy over R\&D management. Assignment may reinforce the identification and long-term ties between a manager and the intellectual property under her charge, so that opportunistic behavior becomes costly in terms of reputation (Baker, et al., 2002), or it may increase division worker's intrinsic sense of autonomy (Puranam et al., 2006). Similarly, assignment of patent rights may be associated with a credible delegation of informal authority, since assignment allows the affiliate to directly contract with outside licensees, without formally requiring headquarters to "sign off" on deals. More simply, assignment may reflect a broader "hands off" orientation. We are agnostic as to which mechanism might be at play, since all evidence points to assignment as associated with increase autonomy. Conversely, it is difficult to argue that such assignments would in any way reduce a division's autonomy. Nonetheless, assignment of patents to affiliates may be sufficient - but not necessary for decentralization, because a business or division inside a firm may have de facto authority over its $R \& D$ and innovation, but still not have any patents assigned to it. As with any proxy measure that lends itself to large-scale empirical analysis, our measure is practical but imperfect, and we admit that there are trade-offs to consider. In our case, there may be sources of unobserved heterogeneity that are not mitigated by our battery of 
controls. Future work should continue to explore both the potential and limits of this empirical approach.

To better understand the implications of our measure, we conducted several interviews with IP managers, attorneys, and high-level executive at firms in a range of industries. Our discussions reinforced the interpretation that assignment is strongly associated with effective delegation of authority in the R\&D process. In fact, not one person interviewed found this association surprising. For example, a Vice President and Chief Patent Counsel for a global medical devices firm opined that patent assignment to affiliates "reflects the underlying structure of the firm," and that it indicates with high certainty that "affiliates enjoy autonomy regarding IP, choice of R\&D projects, and perhaps also in the overall R\&D investment by the division," (confidentiality prevents us from disclosing the managers and companies we interviewed).

\section{[Insert Figure 1 here]}

We also examined the patterns of assignment for prominent firms whose R\&D structure is well known. For example, Figure 1 compares the pattern of patent assignment for two prominent, diversified pharmaceutical and health care companies. For each firm we show the share of patents assigned to their top 30 affiliates (we aggregates as "other" all small affiliates beyond 30), inclusive of the headquarter. We can see that these patterns are markedly different. Johnson and Johnson only has $9.4 \%$ of its patents assigned to headquarters (highly decentralized in our measure), which maps well to its reputation of being "the reference company for being decentralized," as characterized by its own CEO, William Weldon. ${ }^{1}$ By contrast, Abbott Laboratories assigned $59 \%$ of its patents to headquarters. Despite shifting to a more decentralized (and more acquisitive) strategy in the past few years, Abbott has traditionally relied on centralized R\&D (Mayer, 2003). Though there is no systematic way to perform this detailed analysis for our large sample, these and other manual checks were extremely encouraging.

More systematically, we validated our measure by comparing how closely it replicated the categorization by Argyres and Silverman's 2004 study ("AS"), which classified 71 firms as centralized, decentralized, or hybrid based on self-reported organizational structure. Considering that 12 years separate the data in our respective studies, and that AS included some firms that are not listed on American stock exchanges, we were fortunate to have 56 of their 71 firms in our sample. We find that our patent-based measure perfectly matches 38 out of 56 (68\%) firms as

\footnotetext{
${ }^{1}$ http://knowledge.wharton.upenn.edu/article.cfm?articleid=2003
} 
centralized, decentralized, or hybrid. Importantly, 15 out of the 18 mismatches involved hybrids, rather than diametrically opposite classifications. This is significant because it suggests that our misalignment with AS could be due to a sensitivity to thresholds of classification, rather than to our measure pointing in the wrong direction. Impressively, there were only three firms where our respective classifications were diametrically opposed (that is, where our centralized firms were decentralized in AS, or vice-versa). Thus we are confident that our measure is a reasonable empirical proxy for the decentralization of $\mathrm{R} \& \mathrm{D}$.

\subsection{Other variable definitions and measures}

Internal Research focus. Our main measure of internal research is based on scientific publications. We use publication intensity, defined as the number of publications in scientific journal divided by sales, to measure how much the firm invests in internal research. Scientific publications are a commonly accepted measure of a firm's basic science orientation (Gambardella, 1995; Stern, 2004), and firms such as DuPont, IBM, Merck, and Microsoft, which have traditionally relied upon internally generated innovations, have also tended to produce a great number of scientific publications.

We use three supplemental measures to probe the robustness of our results to alternate measures, since the literature suggests a variety of empirical proxies. R\&D intensity is measured as discounted stock of R\&D, divided by lagged sales. R\&D stock is calculated using a perpetual inventory method with a 15\% depreciation rate (Hall, Jaffe, and Trajtenberg, 2005). So the R\&D stock, $G R D$, in year $t$ is $G R D_{t}=R_{t}+(1-\delta) G R D_{t-1}$ where $R_{t}$ is the R\&D expenditure in year $t$ and $\delta=0.15$. Typically, firms that rely upon internal research to fuel growth have higher levels of R\&D intensity. Similarly, we also expect firms with a higher share of breakthrough product innovations to file for more patents from a given R\&D investment, when compared to firms doing relatively more incremental and short-term research. Note that this measure may also reflect a firm's strategy for appropriating rents from R\&D (Cohen et al., 2000), as well as the incentives for patenting it provides its internal researchers. As a result, we also use patent propensity, defined as the number of citation weighted patents divided by R\&D stock. For each patent we compute the number of citations it receives in a period of 15 years since its grant year, and normalize this count by the average number of citations received by all patents that were granted in the same year as the focal patent.

External orientation. We use multiple measures to capture external orientation. Our primary 
measure is share patents acquired, defined as the share of patents within the total stock of the firm's patents that came to the firm via an acquisition, as opposed to having been generated by the firm (including its firm's affiliates). This captures the degree to which a firm relies on externally acquired technology (Capron et al., 1998; Karim, 2006). An ancillary measure is acquirer, a dummy variable that takes the value of one for every year when the firm makes an acquisition (the unit of observation here is firm-year). Our last two measures provide insight into the type of targets that the firm acquires and happens to them post-acquisition. We classify a target as "large" if it had at least 32 (this is the top tertile in terms of patents acquired per transaction) or we classify it as "small" if it had fewer than 5 patents (lowest quartile). Dividing the number of small acquisitions by a firm's total acquisitions gives us our share small. To explore post-merger integration, we divide a firm's count of patent-weighted absorbed acquisitions by the total number of targets, to obtain share absorbed.

Organizational structure. As described earlier, we use share patents assigned, a continuous measure of decentralization, and a discrete classification of firms based on the measure. We classify firms according to tertiles of share of patents assigned, and operationalize using categorical variables. These categories are: centralized (lowest tertile), hybrid (second tertile), and decentralized (third tertile). We use the centralized category as our baseline in all regressions.

Market value. Consistent with a long tradition in the economics of innovation literature (Griliches, 1982), market value is defined as the sum of the values of common stock, preferred stock, and total debt net of current assets. The book value of capital includes net plant, property and equipment, inventories, investments in unconsolidated subsidiaries, and intangibles other than R\&D. Patents Stock is calculated using a perpetual inventory method with a $15 \%$ depreciation rate. Patents stock in year $t$ is calculated as Patents stock ${ }_{t}=P_{t}+(1-\delta)$ Patents stock $_{t-1}$ where $P_{t}$ is the citations-weights flow of patents in year $t$. In an important advance to this methodology, we can account separately for internal and external patents stock, and are thus able to disaggregate how these differently contribute to firm value.

\subsection{Descriptive statistics and evidence of persistence}

Average value of sales in our sample is $\$ 3.4$ billion, and market value is $\$ 5.9$ billion (of which $\$ 3$ billion are in physical assets). As for innovation, average R\&D spending is $\$ 129$ million, patent stock is 174 , and scientific publications is 58 . At the firm level, $33 \%$ of the stock of patents are assigned to affiliates, and $27 \%$ of patents are acquired. 
Our observed measures of strategy are highly persistent over time at the firm level. An analysis of variance (not presented in a table) indicates that between-firm variation accounts for $87 \%, 81 \%$, and $88 \%$ of the total variance for share patents acquired, share patents assigned, and publication intensity, respectively. In other words, the bulk of the variation in our measures is between firms rather than variation over time within a firm. This strongly supports the view that there are reinforcing interactions among the various choices, which may make it difficult or undesirable for firms to abruptly change any of their core strategies. We do not suggest that firms are static. It may be that as firms mature, some may become more "exploitative" rather than "explorative" as they focus on commercialization. Alternatively, more mature firms may be the only ones that can support large internal research, which would imply the opposite. However, as discussed earlier, it took nearly a century for DuPont to go from decentralized to centralized and back. Thus, it may be that this sort of evolution occurs at a pace that is too gradual for our data to capture.

We perform an additional test to measure the stability of our focal strategies over time by comparing a firm's ordinal ranking for each measure at the end of the sample to the ranking on the first year it appears in the sample. Thus, we see whether a firm assigned to a particular quartile in its first year is assigned to a different quartile in the last year. This way of assessing persistence obviates the need to control for changes in the environment or changes in firm size or other such variables.

We observe very little variation in publication intensity within firms over time. Over 91 percent of firms are in the same quartile of publication intensity at the end of the period as they were at the start of the period. Only about 6 percent of firms move up in the distribution at all, and less than 3 percent move up by at two quartiles or more. About 4 percent of all firms move down the distribution, but none drops by more than a single quartile.

We observe slightly more time variation in share patents acquired, with 82 percent of firms not changing their acquisition category, 12 percent of the firms becoming relatively more acquisitionintensive over time, and 6 percent of all firms dropping down at least one quartile. Finally, there is more time variation in share patents assigned, where 59 percent of the firms in our sample do not change their assignment category throughout the sample period. Here, 25 percent of firms move up in decentralization distribution, and the remaining 16 percent of firms move down (i.e., become more centralized relative to the population). Of all the firms that change quartile (up or down), nearly three quarters move by only one quartile in rank over the entire sample period. In sum, we find that the bulk of the variation is across firms, despite the fact that our sample 
period (1975-2007) witnessed many changes in the environment, including the energy crises of the 1970s, the merger waves of the 1980s, the rise of the high-tech sector, and globalization. This persistence makes it meaningful to speak of coherence across choices that firms make along the focal dimensions of innovation strategy namely internal research, external knowledge, and organizational structure.

\section{[Insert Table 1 here]}

\subsection{Relationships among structure, external orientation, and inter- nal research}

\subsubsection{Non-parametric analysis}

We begin by exploring the relationships between organization, acquisitions, and internal research in Table 2. Specifically, we look at how both share patents acquired and publication intensity vary across firms with varying levels of decentralization. Consistent with our coherence arguments, we find discrete patterns of heterogeneity among firms, where centralization is associated both with lower reliance on acquired patents and with greater publication intensity.

Table 2 shows three important relationships. First, there is significant variation in size across decentralization categories (columns 1 and 2). Decentralized firms have the lowest patent stock. Hybrid firms are the largest both in terms of sales and number of patents. Centralized firms are smaller than decentralized firms in terms of sales, but they have close to double the number of patents. This variation in size and patenting highlights the importance of controlling for firm size in our parametric explorations. As well, it suggests that even though hybrids are classified based on our decentralization measure, they need not be similarly positioned in other dimensions. In fact, as we shall show, hybrids are not always along the continuum between centralized and decentralized. Future work should further explore the unique attributes of this group.

Second, in column 3 we see that average share of acquired patents increases steeply as we move from centralized firms (11\% of patents acquired) to decentralized firms (87\% of patents acquired). In unreported analyses, we find that the same pattern of results holds when we examine the percentage of firms that are classified in the top tertile of share patents acquired: only $11 \%$ of centralized firms are in the top tertile of share patents acquired, compared to $57 \%$ of decentralized firms.

An important goal for this study is to better understand the relationship between structure 
and external orientation. We further explore this in Columns 4-8, which show a strong positive relationship between the two. We distinguish between two types of acquired units. Dissolved units are those that cease to operate independently and consequently transfer their patents to the parent. Conversely, kept units not only retain the patents that they had prior to acquisition but also continue to be assigned new patents generated post-acquisition. As shown in Columns 4 and 5, a firm's acquisition volume is highly correlated with the relationship between decentralization and external orientation. However, it is important to note that this relationship is also driven by how the firm deals with acquisitions, not simply by how acquisitive the firm is. This is because firms vary in the degree to which they let acquisitions remain independent (which is the channel through which acquisitions lead to decentralization), as well as in the size of the target firms that they acquire. Column 4 shows that centralized firms make substantially fewer acquisitions than hybrid or decentralized firms (3.5 versus 10.8 and 12.6 total acquisitions over the study period, respectively). Normalizing number of acquisitions by sales (column 5), suggests that the negative association between centralization and acquisitions is nearly linear. While centralized firms make 1.9 acquisitions per billion of dollar in sales, hybrids make 3, and decentralized firms make 5.3 acquisitions. More importantly, there is a clear distinction in post-acquisition absorption strategy (column 6). Centralized firms absorb 64\% of their targets, compared to $42 \%$ for hybrids and only $21 \%$ for decentralized firms.

Columns 7 and 8 present evidence on average size of the acquired pool of patents. Centralized firms acquired substantially smaller portfolios, averaging 26 patents per deal, while there is little difference between hybrid and decentralized firms, which both average 50 patents per acquisition. As shown in column 8, there appears to be systematic variation in acquisition size. We classify acquired affiliates as small if the number of patents they hold at the year of acquisition is in the lowest 25 percent of the distribution of number of patents by acquired firms. 61 percent of the targets by centralized firms are classified a small, as compared to 43 percent by hybrid, and 37 percent by decentralized firms. This finding is significant because it points to one reason for the differences in absorption rates. Smaller acquisitions, possibly representing young technologybased firms, should be easier to absorb into an existing division, whereas large acquisitions are both harder to integrate and also more capable of operating as a standalone subsidiary. Later in the analysis, we show that even after controlling for characteristics of the acquiring firm, small acquisitions are more likely to be absorbed (Column 5 in Table 3). In sum, we find that the relationship between acquisition and decentralization is driven not only by how acquisitive the firm is, but also by the relative size of the acquisition (in terms of patents) and the extent to 
which acquired targets are kept independent or integrated into the parent.

These findings are important because structural integration is one of the levers that managers use to shape both the nature of research and the structure of the firm (Haspeslagh and Jemison, 1991; Puranam, Singh, and Zollo, 2006). Thus, regardless of a firm's rate of acquisition, the decision to absorb or not absorb may ultimately have the bigger effect on how decentralized it is (for example Microsoft acquires a lot, yet remains centralized). However, the decision to absorb may be related to the nature of research that a firm performs, if basic research involves resource recombination, which in turn may require the absorption of the acquired entity (Capron, Dussauge, and Mitchell, 1998). Alternatively, the decision to absorb may reflect a mix of coherence and inertia (i.e. centralized firms have so many complementary systems and structures that integration is less costly, while it may also have a managerial philosophy which favors absorption).

Third, we find a striking negative relationship between structure and internal research. Centralized firms publish much more per dollar of sales revenue than decentralized firms, and they have substantially higher R\&D intensity. As shown in column 10, centralized firms have the highest ratio of publications to sales (21.4), decentralized have the lowest ratio (6.6), and hybrid firms lie in the middle (10.5). A similar picture emerges if we use R\&D intensity instead of publication intensity. Column 12 shows that centralized firms have an R\&D to sales ratio of 0.43 , as compared to a ratio of 0.29 for hybrid firms, and 0.21 for decentralized firms.

\section{[Insert Table 2 and Figure 2 here]}

The patterns of results reported in table 2 capture the coherence logic. We show this more starkly in figure 2, which plots how the values for external orientation (Column 3, Table 2) and research orientation (Column 10, Table 2) move in opposite directions. External orientation increases with the degree of decentralization whereas research orientation decreases with decentralization.

Because the simple relationships in Tables 2 and 3 may reflect industry effects, as well as differences in firm characteristics, we next perform a parametric analysis that controls for these factors.

\subsubsection{Parametric analysis}

Our findings thus far serve as large-scale validation and extension of earlier studies. However they are not conditioned on important variables that may drive the observed relationships 
between our focal variables. To mitigate such concerns, we move to parametric analysis. We emphasize that the patterns of association we report should not be interpreted in a causal sense-we do not argue that a choice made in one dimension should determine a choice in another dimension. Instead, we show the conditional correlations between our measures, while gradually removing sources of co-variation such as firm size and industry effects.

Table 3 presents the conditional relationship between the acquisition of external knowledge, internal research, and decentralization. We cluster standard errors by firm, and include 248 fourdigit SIC dummies as industry fixed effects. Columns 1-7 present the conditional correlation of decentralization with external orientation, and Columns 8-13 present the conditional correlation of decentralization with internal research.

Column 1 shows a very large coefficient estimate on the dummy for decentralization (0.75), and a much lower estimate on the coefficient on the dummy for hybrid (0.17). In column 2 we also control for publications intensity (the lagged ratio between publications stock and sales) as a measure of internal research. The coefficient estimates on structure are not affected by controlling for publications intensity. The coefficient estimate on publications intensity is negative and significant, indicating that, conditional on structure, higher internal research is associated with less acquisition activity. In unreported specifications we explore the extent to which structure conditions the publications-acquisitions relationship. Estimating the specification from Column 2 without the structure dummies yields a large and statistically significant coefficient for publication intensity of -0.1 , whereas controlling for structure causes the coefficient to drop in half. In other words, structure strongly conditions the negative relationship between publication activity and firms' acquisition of external knowledge. We find similar patterns with alternative measures of research orientation, such as the lagged log of the ratio of R\&D stock to sales. Not controlling for structure, there is a strong negative relationship between R\&D intensity and external orientation: the coefficient estimate on R\&D intensity is -0.12 and is highly significant (a standard error of 0.04). Controlling for structure, however, this estimate drops to -0.03 and is no longer significant.

In additional unreported specifications, the results remain unchanged when we restrict the sample to firms that make at least one acquisition, indicating that our estimates are not likely to stem from comparing acquiring to non-acquiring firms.

These results suggest that firms with high internal research investments acquire less external knowledge, not just because of their internal R\&D focus, but also because such firms also have a more centralized structure, which itself is also correlated with fewer acquisitions. In other words, 
this finding suggests that analyzing the relationship between internal and external knowledge, without accounting for the organizational structure of the firm, may be misleading.

Columns 3 to 5 show that both centralized firms and research-intensive firms, as well as firms that tend to make smaller acquisitions, are more likely to absorb their acquisitions. In unreported specifications we find that the estimated coefficients of publication intensity and share patents assigned are largely independent of whether the other measure is included or not. This suggests that both centralization and a focus on internal research are associated with a greater likelihood that the target is absorbed. This supports the notion that centralized firms would acquire more nascent external technology to integrate into their existing research (Capron et al., 1998; Karim, 2006), whereas decentralized firms may acquire more developed technology that is closer to being commercialized (e.g., Cisco's "acquire and develop" model).

We next examine the relationship between the share of small acquisitions and structure (columns 6 and 7). We find that centralized firms are more likely to engage in smaller acquisitions. Surprisingly, we find no systematic relationship between internal research and the share of small acquisitions (column 7). In unreported results where we do not control for structure, the coefficient estimate on publications intensity is once again small and insignificant. In other words, whether conditional on structure or by itself, publications intensity is not correlated with the share of small acquisitions. This is a surprising result, particularly since smaller acquisitions are more likely to be absorbed (Column 5), and internal research is associated with greater likelihood of absorption of targets (Column 4). We find the same pattern when we measure internal research using $R \& D$ intensity instead of publications intensity. Whether this reflects a limitation of our measures or a deeper puzzle is a topic for future research.

In sum, Columns 1 to 7 support our conjecture that, at least in part, internal research is related to external knowledge acquisition because internal research is also related to organizational structure, which in turn is related to external knowledge. Columns 8 to 13 investigate the same issue but shifts the analysis to concentrate on the nature of internal research and its relationship to both structure and external acquisitions. We supplement our main measure of internal research investment with $\mathrm{R} \& \mathrm{D}$ stock and patent propensity. We use logs of both publication and R\&D stock. By using log of sales as a control, we allow for a more flexible relationship than if we simply used the ratio of publication to sales or $R \& D$ to sales as a dependent variable.

In columns 8 and 9 we regress publications stock as the dependent variable. We find a strong negative relationship between decentralization and scientific publications: decentralized firms 
publish 48 percent less than centralized firms. There is no difference, however, between hybrid firms and centralized firms (Column 8). We also find a negative relation between publications and share patents acquired (column 9), however, it is not statistically significant when controlling for structure. When not controlling for structure (not reported), the coefficient estimate on share patents acquired is very large in absolute value and is highly significant (-0.31 with a standard error of 0.12). Organization structure thus is significantly associated with investment in internal research, even after conditioning on external knowledge sourcing. This finding, that the relation between internal research and external orientation is strongly mediated by structure, warrants further study.

Columns 10 to 13 show that similar patterns obtain when we repeat these tests using our alternative measures of internal research focus. The pattern of our findings is strongly consistent across all specifications. One notable exception is Column 13, where we find a strong negative relationship between external orientation and patent propensity, even when controlling for structure. In unreported specifications, we find weaker results for citations per patent, where hybrid firms show the highest citations per patent.

Overall, Table 3 shows that the simple patterns reported in Tables 2 are not just due to differences in industry, firm size, or time. As we expected, the choices of firms along the three focal elements of innovation strategy are not randomly distributed, so the choice along one dimension is systematically predictive of choices in the other two dimensions. Moreover, our results also point to the intriguing (and understudied) role that organizational structure may play in the overall innovation strategy. Whereas innovation scholars have focused on the relationship between internal research and external knowledge, Table 3 suggests that internal structure significantly conditions the relationship between internal research and acquisition of external knowledge.

One must be cautious in interpreting these patterns because they may reflect differences in the precision with which we measure various concepts. Yet, this calls for further research, both theoretical and empirical, into the ways in which the internal organization of the firm interacts with investments in internal and external knowledge. We still know very little about the origins of structure - whether it arises alongside strategy, for example, or is driven by strategy - and this focuses attention on why this neglected pillar of organizational research (Gavetti, Levinthal, and Ocasio, 2007) needs more attention.

\section{[Insert Table 3]}




\subsection{Firm Market Value}

We have shown that centralization is associated with investment in basic research while decentralization is associated with a strong emphasis on accessing external innovations. We have also argued that these patterns may reflect the underlying innovation strategy of the firm. If this so, the innovation strategy of a firm should have direct implications for how the firm creates value: Centralized firms' internally generated knowledge should be a key source of value creation, whereas external knowledge should drive market value for decentralized firms. In other words, we would expect that unmeasured "intangible assets" should account for a greater share of value for centralized firms relative to decentralized firms, since internal investments in research are more difficult to measure than acquisitions of external knowledge. Indeed, we find that the average "market to book" ratio (commonly known as Tobin's $Q$ ) is 1.5 for centralized firms, but only 1.3 for decentralized firms.

A more consequential implication of this is that not only should centralized firms have more intangible assets, the intangible portion of their assets should also be more heavily related to internal knowledge. Conversely, the intangible assets of decentralized firms should be related more closely to acquisitions of external knowledge. We are able to empirically examine this by estimating a version of the value function approach proposed by Griliches (1981). We stress variation across firms rather than within-firm variation, because as we have already shown, the vast bulk of the variation in internal structure is across firms, rather than within firms.

Table 4 presents the estimation results. We begin by estimating a standard value function, using two measures of knowledge stock - R\&D stock and patent stock. To control for patent quality we weight each patent by the ratio between the number of citations it receives and one plus the average number of citations received by all patents that were granted in the same year (one is added to both numerator and denominator to avoid zero weights). In the baseline specifications we control for the log of lagged assets, industry fixed effects (using 197 four-digit SIC dummies), and year effects. Later in the analysis we also control for sales and sales growth, as well as split the sample by technical diversification and size.

Columns 1 and 2 show that R\&D stock and patent stock are both positively associated with value. We also see that their effects are largely independent, as the coefficient of R\&D stock falls only slightly when patent stock is added. Column 3 distinguishes between patents that are generated internally and "external" patents that are acquired via M\&A transactions. Both internal and external patents seem positively associated with market value, and have very 
similar coefficients. However, as we shall show, these average results mask stark differences across firms with different organizational structures.

Columns 4 to 6 split the sample into tertiles of decentralization using the same classification from Tables 2 and 3. The first striking finding in column 4 is that for centralized firms R\&D stock has a very large and highly significant positive correlation with market value (a coefficient estimate of 0.16 ), but whereas internal patents continue to be associated with value, external patents cease to matter. On the other hand, we see the opposite pattern for decentralized firms (column 6). Here we find a large positive correlation between external patents and value for decentralized firms (coefficient estimate of 0.08), and an R\&D coefficient estimate which is less than half of what we observe for centralized firms. This pattern is consistent with the idea that there are different routes to value creation, which require different supporting organizational structures. Firms relying on internal research to create value should find centralization more compatible with their objective. Conversely, a decentralized firm should be more likely to derive value from acquired patents.

Columns 7 to 9 add sales and sales growth as controls. The patterns regarding R\&D stock remains robust. But there is an interesting change in the estimate on external patents for decentralized firms. Controlling for sales and sales growth, this coefficient drops to 0.05 (not statistically significant) from an estimate of 0.08 without these controls. In fact, this drop is mostly attributed to controlling for sales growth: when excluding sales growth but still controlling for sales, the coefficient estimate on external patents stock is 0.07 and is statistically significant at the 1 percent level. This intriguing result points to a fruitful avenue for future research to investigate whether decentralized firms are more reliant upon growth to create value, and do so by commercializing and scaling up external innovations, whereas centralized firms use internally generated innovations.

If what we are capturing is related to the importance of alignment between organizational structure and the knowledge-sourcing strategy, we should expect our results to be stronger for larger firms and for firms that operate in a diverse range of businesses and technologies, relative to smaller firms and firms that are narrowly focused. This is because for small and undiversified firms, the formal organizational structure will be more malleable (Tripsas and Gavetti, 2000). To probe this conjecture we divide firms by their degree of technical diversity. We measure technical diversity by the number of technology areas in which the firm patents. We classify firms as having low or high technological diversity according to the sample median value of the number of three-digit technology classes the firm patents in. 
Finally, we note that for centralized firms, the amount of assets held account for a much smaller share of the value than in decentralized firms, consistent with the simple differences in Tobin's Q discussed earlier. Even more intriguingly, sales growth is considerably more strongly associated with market value in decentralized firms than in centralized firms. However, interpreting market-value regression coefficients is not straightforward (see for instance, Czarnitzki et al., 2006), and we must leave it to more future research with more fine-grained measures to pursue these tantalizing lines of inquiry.

\section{[Insert Table 4 here]}

Despite the coarseness of the measurement, Table 5 shows that the contrast between R\&D stock and external patents appears to be substantially driven by diversified firms and by large firms. We acknowledge that this measure is imperfect, because it measures technical diversity rather than product market diversity, and because it is likely highly correlated with the scale of the firm's patenting activities. Future work should explore how these results hold up with more granular business-level data.

Columns 1-6 show the results for diversified and specialized firms. Among the set of technically diversified firms, centralized firms derive considerable value from internal R\&D, whereas decentralized firms derive little value from internal R\&D (coefficient estimates of 0.16 versus -0.01). Centralized firms derive less value from external patents than do decentralized firms, although the difference in the coefficients is not statistically significant (0.03 compared to 0.05). By contrast, the fit between internal structure and knowledge sourcing in creating value seems to matter less for specialized firms. All firms derive value from internal R\&D, although the reliance is more marked among centralized rather than decentralized firms, and external patents appear to be uncorrelated with value.

Diversified firms tend to be large as well. To explore this aspect, we divided firms by size, classifying firms as large if their sales were above the median level of sales. Columns 7 to 12 show that patterns observed in Table 4 are also more marked for large firms, implying that we cannot confidently distinguish whether the greater salience of structure in such firms reflects the effects of diversity or size. In large firms, R\&D stock is associated with value for centralized

firms but not decentralized firms (coefficient estimate of 0.09 compared to 0.01). Conversely, external patents are associated with value in decentralized firms but not in centralized firms (coefficient estimate of 0.10 compared to 0.03 ). 
Overall, our findings support the interpretation that firms that rely upon internal research to create value are best served by a centralized organization, in contrast to firms that rely upon external knowledge, especially in large or technically diversified firms. More importantly, firms seem to be able to derive proportionally more or less value from internal or external knowledge depending on their overall set of characteristics, even when they utilize both internal and external as inputs.

\section{[Insert Table 5 here]}

\subsection{Robustness}

In a number of unreported tests, we probed the robustness of the relationships documented in Table 3. We summarize these tests briefly.

Size: We checked the sensitivity of our results to firm size by excluding very small and very large firms from the sample (lowest and highest sales deciles). This ensures that the conditional correlations presented above are not driven by comparing very small to very large firms. We find similar results to those reported here, reassuring us that cross-firm size variation does not drive the main relationships in our data.

Geography: Though there is a growing literature on the geographical location and management of R\&D activities (Leiponen and Helfat, 2011; Singh, 2008), the question of geography is logically distinct from the question of internal organization. For example, as Singh (2008) puts it, a firm could have a decentralized formal organization even with relatively small number of R\&D locations, while another firm might have a much more centralized organization despite having a much greater number of R\&D locations. Though the location of activities obviously has implications for how they should be managed, other considerations such as access to users, talented researchers, or knowledge spillovers are also important geography considerations (Kogut, 1991; Jaffe, 1986). Nonetheless, in order to mitigate against contamination from impacts of geography on our sample we add a vector of 197 location dummies which control for the share of patents that each firm generates within a given Core-Based Statistical Area (CBSA). The results in Tables 4 and 5 are largely unchanged.

Affiliates: We also confirm that our results continue to hold when we exclude from our sample 212 firms with no affiliates. By construction, their share of assigned patents is zero (thus these firms are classified as centralized). To test whether our set of relationships is driven by the distinction between firms with and without affiliates, we estimate the main specifications 
for a sample that includes only firms with at least one affiliate, regardless of whether the affiliate patents or not. Demonstrating that our results continue to hold also within a sample of firms that have at least one affiliate eliminates the concern that the results are driven by comparing firms with and without affiliates.

Patenting scale: Another potential concern relates to firms that have relatively few patents. Our measure of decentralization is based on the ratio between assigned patents and total patents held by the firm. This ratio is likely to be less informative for firms with a small number of patents. We estimate the main specifications for a sample that excludes firms with fewer than 15 patents in total, and find results similar to those reported here.

\section{Discussion and Conclusion}

In this paper we exploit rich new data on over a thousand American firms to explore the interplay among three important dimensions of innovation strategy: R\&D organizational structure, external knowledge sourcing, and internal research focus. A new measure of decentralization allows us to perform the first such large-scale study, documenting patterns supporting the view that firms make consistent and coherent choices along these three dimensions. This yields some important contributions. First, we validate prior findings in the literature that have shown a link between structure and the nature of innovation (Argyres and Silverman, 2004; Lerner and Wulf, 2007), with an empirical approach that mitigates small sample problems and improves replicability. Second, we document a pattern that strongly suggests a positive link between decentralization and external orientation. To our knowledge, this relationship has not received any attention in the literature. These are valuable contributions, especially given the growing awareness within the strategy field of the need for more studies that document "just the facts" (Oxley et al., 2010; Hambrick, 2007; Bettis, 2012).

Third, we go beyond mere descriptions, as our analysis clarifies and extends prior results that relied on simpler one-to-one relationships. We find that structure strongly conditions the negative relationship that has been shown between internal research and the acquisition of external knowledge. Documenting this contingency is interesting and important beyond our setting. Though recent work has highlighted the importance of structure as a "forgotten pillar" of organizational theory (Gavetti, et al., 2007; Joseph and Ocasio, 2012), organizational structure remains stubbornly difficult to observe, and its role in shaping information processing and incentives continues to puzzle managers and researchers (Wulf, 2012). Consistent with the 
implications of Karim and Mitchell's (2004) findings, we also find that internal and external outputs provide different contributions to different firms. Whereas centralized firms derive more value from internal $\mathrm{R} \& \mathrm{D}$, decentralized firms do so from externally acquired patents.

It is likely that firms that innovate primarily by developing knowledge internally favor investments in more basic, long-term research and do not rely much on incremental research that merely improves existing goods and services. Typically, such basic research is best centralized because individual business units are unlikely to support it adequately. Our findings suggest that these firms rely less on external knowledge, and may use it principally to complement their internal knowledge. By contrast, other firms may be unwilling or unable to make the same large investments in internal research to fuel innovation and growth. Their internal R\&D is likely to be focused on improving existing products and processes, which is best managed by the business units that produce those products and services. Our findings suggest that such firms are more likely to look outside for new technologies. Given limited internal capability for evaluating and assimilating nascent technologies, they may favor the acquisition of proven technologies, embodied within target firms that can operate independently and contribute to the commercialization efforts.

Neither strategy is intrinsically better, and in fact most firms do a mix of both. Firms choose more of one or the other based on their particular context, which may be shaped by their initial founding conditions and capabilities, their environment, and how their capabilities and environments evolve (Nadler and Tushman, 1997). What may matter more is how a particular combination of strategies maps to the firm's capabilities. The upshot is that different types of knowledge strategies can create value, if matched to the right context and aligned with the appropriate organizational structure.

Though our empirical strategy generates new insights from the concurrent examination of these various strategic choices and outcomes, it is not meant to establish the direction of causality. Future work should further exploit our novel measure of decentralization, as well as time and exogenous variation in order to better explain the systematic patterns we have described. But just as importantly, our empirical findings should inform future theory development, in the quest to understand the link between innovation strategy and structure. In particular, we highlight the importance of organizational structure as an integral part of corporate strategy. From a normative perspective, our paper should alert managers to the perils of prescriptions which do not account for the three main facets of R\&D strategy. For example, given the role of structure in conditioning the relationship between internal development and external knowledge 
integration, it is unlikely that innovation strategy can be charted using a simple "make vs. buy" logic, if this does not take into account the complex role played by organizational structure. Conversely, knowledge-intensive firms contemplating radical change in terms of increasing or decreasing their centralization should take into account the way in which structure will shape other dimensions of innovation strategy.

\subsection{Acknowledgements}

We thank Marco Ceccagnoli, Tom Hubbard, Will Mitchell and two anonymous reviewers for excellent comments on different versions on this paper. We also thank conference and seminar participants at Georgia Tech, Harvard Business School, HEC Paris, IFN Stockholm, London Business School, NBER, Northwestern University, Universidad Carlos III de Madrid, UNC Chapel Hill, INFORMS, and The University of Southern California.

\section{References}

Ahuja, G, and Katila, R (2001). Technological acquisitions and the innovation performance of acquiring firms: A longitudinal study. Strategic Management Journal, 22(3): 197-220.

Argyres, N S, and Silverman, B S (2004). R\&D, organization structure, and the development of corporate technological knowledge. Strategic Management Journal, 25(89): 929-958.

Arora, A, Fosfuri, A, and Gambardella, A (2001). Specialized technology suppliers, international spillovers and investment: evidence from the chemical industry. Journal of Development Economics, 65(1): 31-54.

Arora, A, and Gambardella, A (1994). The changing technology of technological change: general and abstract knowledge and the division of innovative labour. Research Policy, 23(5), 523-532.

Baker, G P, Gibbons, R, and Murphy, K J (2002). Relational contracts and the theory of the firm. Quarterly Journal of Economics, 117(1), 39-84.

Belenzon, S, and Berkovitz, T (2010). Innovation in business groups. Management Science, 56(3), 519-535.

Bettis, R. (2012).The Search for Asterisks: Compromised Statistical Tests and Flawed Theories. Strategic Management Journal, 33, 108-113.

Capron, L, Dussauge, P, and Mitchell, W (1998). Resource redeployment following horizontal acquisitions in Europe and North America, 1988-1992. Strategic Management Journal, 19(7), 631-661.

Cassiman, B, and Veugelers, R (2006). In search of complementarity in innovation strategy: Internal R\&D and external knowledge acquisition. Management Science, 52(1): 68-82.

Cohen, W M, and Levinthal, D A (1990). Absorptive capacity: A new perspective on learning and innovation. Administrative Science Quarterly, 35(1): 128-152. 
Czarnitzki, D, Hall, B H, and Oriani R, (2006), 'The Market Valuation of Knowledge Assets in US and European Firms' in Derek L. Bosworth and Elizabeth Webster (eds.), The Management of Intellectual Property, Cheltenham: Edward Elgar.

Drazin, R, Van deVen, A. (1985). Alternative forms of fit in contingency theory. Administrative Science Quarterly, 30(4), 514-539.

Fang, C, Lee, J, \& Schilling, M (2010). Balancing exploration and exploitation through structural design: The isolation of subgroups and organizational learning. Organization Science, $1-45$.

Fleming, L (2001). Recombinant uncertainty in technological search. Management Science, 47(1): $117-132$.

Galbraith, J R (1977). Organization design. Reading, MA: Addison-Wesley.

Gambardella, A (1995). Science and innovation: The US pharmaceutical industry during the 1980s. Cambridge, MA: Cambridge University Press.

Gavetti, G, Levinthal, D, and Ocasio, W (2007). Perspective-neo-Carnegie: The Carnegie School's past, present, and reconstructing for the future. Organization Science, 18(3): 523-536.

Griliches, Z (1981). Market value, R\&D, and patents. Economics Letters, 7(2): 183-187. Elsevier.

Hambrick, D C (2007). The field of management's devotion to theory: Too much of a good thing? Academy of Management Journal, 50(6): 1346-1352.

Helfat, C E, and Eisenhardt, K.M. (2004). Inter-temporal economies of scope, organizational modularity, and the dynamics of diversification. Strategic Management Journal, 25: 1217-1232.

Henderson, R M, and Cockburn, I M (1994). Measuring competence? Exploring firm effects in pharmaceutical research. Strategic Management Journal, 15(S1), 63-84.

Hitt, M, Hoskisson, R and Ireland, R D (1990). Mergers and acquisitions and managerial commitment to innovation in M-form firms. Strategic Management Journal, 11: 29-47.

Hoskisson, R E, Hitt, M A, and Hill, C W L (1993). Managerial incentives and investment in R\&D in large multiproduct firms. Organization Science, 4(2), 325-341.

Hounshell, D A, and Smith, J (1988). Science and corporate strategy: Du Pont R8BD, 19021980. New York: Cambridge University Press.

Jaffe, A. (1986). Technological opportunity and spillovers of R and D: Evidence from firms' patents, profits, and market value. The American Economic Review, 76(5): 984-1001.

Joseph, J, and Ocasio, W (2012). Architecture, attention, and adaptation in the multibusiness firm: General electric from 1951 to 2001. Strategic Management Journal, 33, 633-660.

Karim, S (2006). Modularity in organizational structure: The reconfiguration of internally developed and acquired business units. Strategic Management Journal, 27(9): 799-823.

Karim, S, and Mitchell, W (2004). Innovating through acquisition and internal development: A quarter-century of boundary evolution at Johnson and Johnson. Strategic Management Journal, 37: $525-547$. 
Karim, S, and Mitchell, W (2000). Path-dependent and path-breaking change: Reconfiguring business resources following acquisitions in the U.S. medical sector, 1978-1995. Strategic Management Journal, 21(10-11): 1061-1081.

Katz, R, and Allen, T J (1982). Investigating the Not Invented Here (NIH) syndrome: A look at the performance, tenure, and communication patterns of $50 \mathrm{R} \& \mathrm{D}$ project groups. $R \mathscr{E} D$ Management, 12(1): 7-19.

Kay, N (1988). The R\&D function: Corporate strategy and structure. In G. Dosi, C. Freeman, R. Nelson, G. Silverberg, and C. Soete (Eds.), Technical Change and Economic Theory. London.

Kogut, B (1991). Country capabilities and the permeability of borders. Strategic Management Journal, 12(S1), 33-47.

Kogut, B, and Zander, U (1993). Knowledge of the firm and the evolutionary theory of the multinational corporation. Journal of International Business Studies, 34(6), 516-529.

Leiponen, A, and Helfat, C E (2011). Location, decentralization, and knowledge sources for innovation. Organization Science, 22(3): 641-658.

Lerner, J, and Wulf, J (2007). Innovation and incentives: Evidence from corporate R\&D. Review of Economics and Statistics, 89(4): 634-644.

Mayer, H (2003). Corporate restructuring and the creation of the innovation millieu: The case of a second-tier high technology region. Conference proceedings: Clusters, Industrial Districts and Firms: the Challenge of Globalization. Moderna, Italy.

Mowery, D C, Oxley, J E, and Silverman, B S (1996). Strategic alliances and inter-firm knowledge transfer. Strategic Management Journal, 17: 77-91.

Nadler, D A, and Tushman, M L (1997). Competing by Design. Oxford University Press, New York

Oxley, J E, Rivkin, J, and Ryall, M D (2010). The Strategy Research Initiative: Recognizing and encouraging high-quality research in strategy. Strategic Organization, 8(4), 377-386.

Puranam, P, and Srikanth, K (2007). What they know vs. what they do: How acquirers leverage technology acquisitions. Strategic Management Journal, 825(April): 805-825.

Puranam, P, Singh, H, and Zollo, M (2006). Organizing for innovation: Managing the coordinationautonomy dilemma in technology acquisitions. The Academy of Management Journal, 49(2): 263-280.

Rivkin, J, and Siggelkow, N (2003). Balancing search and stability: Interdependencies among elements organizational design. Management Science, 49(3), 290-311

Rosenberg, N (1979). Technological interdependence in the American economy. Technology and Culture, 20(1): 25-50.

Siggelkow, N (2011). Firms as Systems of Interdependent Choices. Journal of Management Studies, 48(5), 1126-1140.

Singh, J (2008). Distributed R\&D, cross-regional knowledge integration and quality of innovative output. Research Policy, 37(1): 77-96.

Stern, S (2004). Do scientists pay to be scientists? Management Science, 50(6): 835-853. 
Teece, D J, Rumelt, R., Dosi, G, and Winter, S (1994). Understanding corporate coherence. Innovation, organization and economic dynamics: selected essays, 23: 264. Edward Elgar Publishing.

Tripsas, M, and Gavetti, G (2000). Capabilities, cognition, and inertia: Evidence from digital imaging. Strategic Management Journal, 21(10-11), 1147-1161.

Wulf, J (2012). The flattened firm-Not as advertised. California Management Review, 55 no. 1

Zollo, M, and Singh, H (2004). Deliberate learning in corporate acquisitions: Post-acquisition strategies and integration capability in U.S. bank mergers. Strategic Management Journal, 25(13): 1233-1256. 


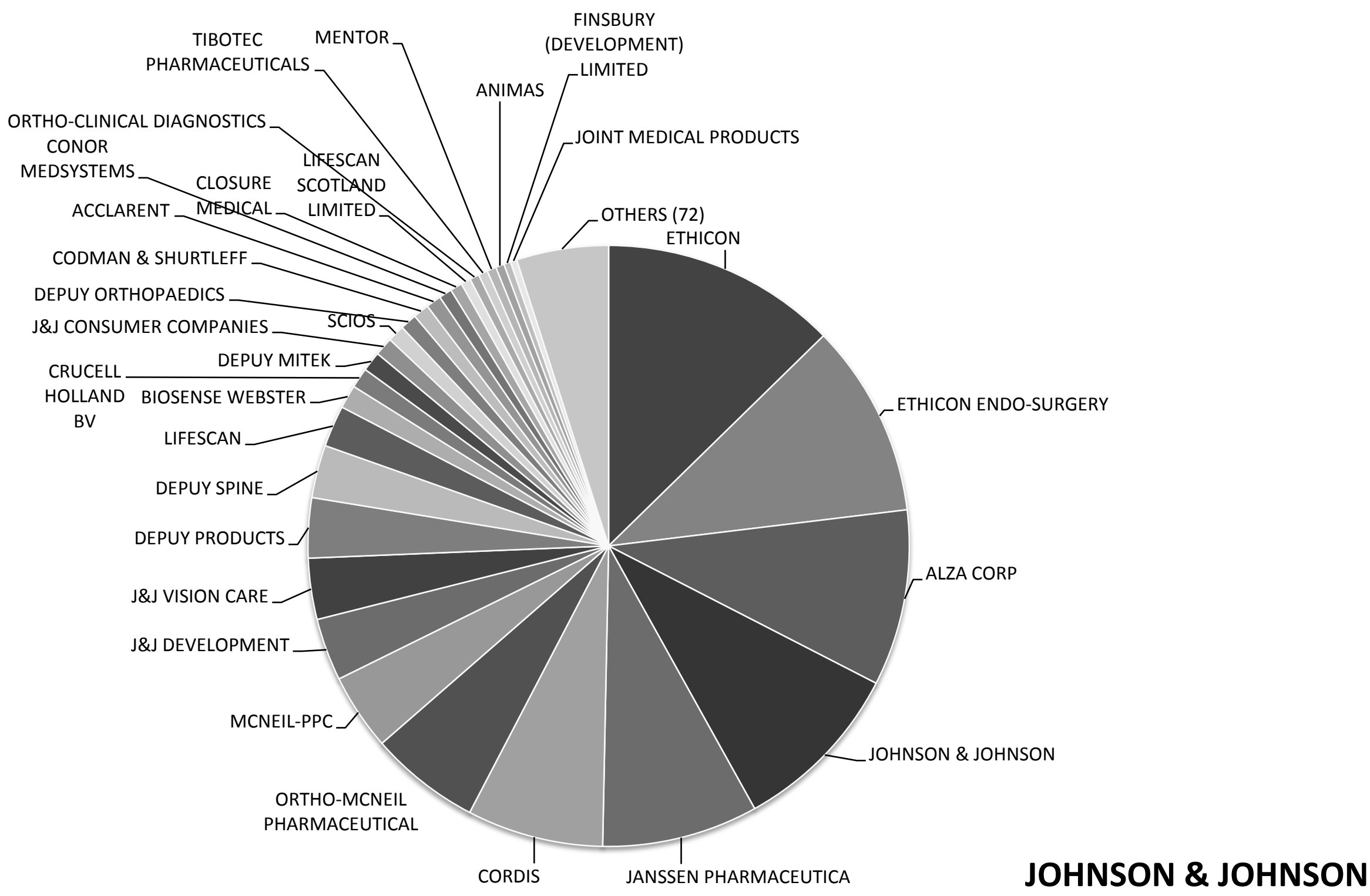

Figure 1a: An example of a decentralized pattern of patent assignment. Top 30 affiliates shown 


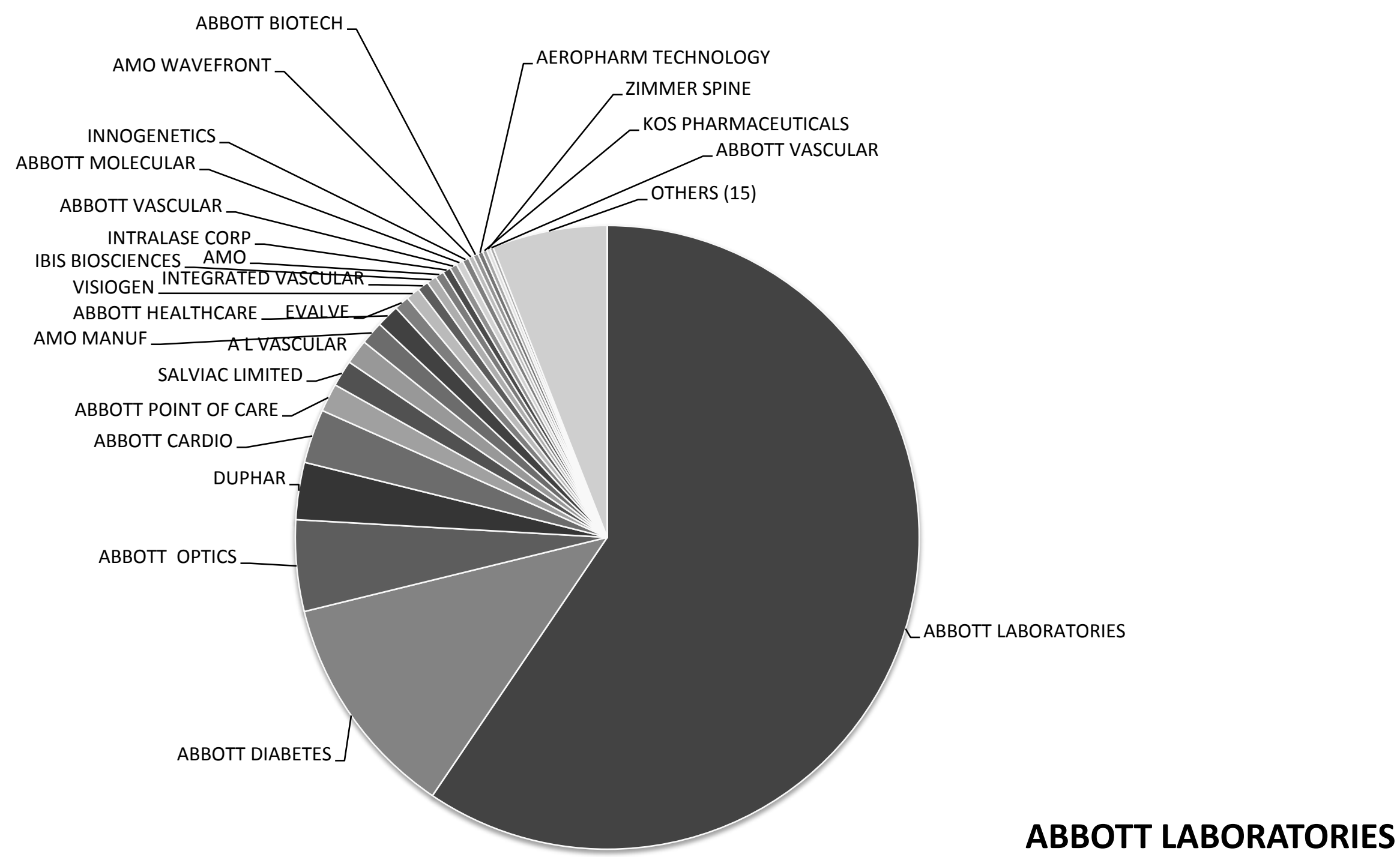

Figure 1b: An example of a centralized pattern of patent assignment. Top 30 affiliates shown 
Table 1. Summary Statistics for Main Variables

\begin{tabular}{|c|c|c|c|c|c|c|c|}
\hline \multirow[b]{2}{*}{ Variable } & \multirow[b]{2}{*}{ \# Obs. } & \multirow[b]{2}{*}{ \# Firms } & \multirow[b]{2}{*}{ Mean } & \multirow[b]{2}{*}{ Std. Dev. } & \multicolumn{3}{|c|}{ Distribution } \\
\hline & & & & & $10^{\text {th }}$ & $50^{\text {th }}$ & $90^{\text {th }}$ \\
\hline Share patents assigned & 11,304 & 1,014 & 0.33 & 0.42 & 0 & 0.03 & 1 \\
\hline Share patents acquired & 11,304 & 1,014 & 0.27 & 0.41 & 0 & 0 & 1 \\
\hline Publications flow & 11,304 & 1,014 & 10 & 58 & 0 & 0 & 8 \\
\hline Publications stock & 11,304 & 1,014 & 58 & 389 & 0 & 0 & 20 \\
\hline$R \& D$ expenditures (\$mm) & 11,304 & 1,014 & 129 & 498 & 0 & 10 & 237 \\
\hline$R \& D$ stock $(\$ \mathrm{~mm})$ & 11,304 & 1,014 & 489 & 1,820 & 0 & 34 & 945 \\
\hline R\&D stock / Sales (\$mm) & 11,304 & 1,014 & 0.30 & 0.71 & 0 & 0.10 & 0.64 \\
\hline Patents flow & 11,304 & 1,014 & 26 & 101 & 0 & 2 & 46 \\
\hline Patents stock & 11,304 & 1,014 & 174 & 664 & 2 & 19 & 314 \\
\hline Market value (\$mm) & 11,304 & 1,014 & 5,920 & 20,278 & 33 & 677 & 12,208 \\
\hline Sales $_{t-1}(\$ \mathrm{~mm})$ & 11,304 & 1,014 & 3,410 & 9,805 & 35 & 600 & 8,205 \\
\hline Assets $_{t-1}(\$ \mathrm{~mm})$ & 11,304 & 1,014 & 3,017 & 9,681 & 24 & 397 & 7,328 \\
\hline Number of employees & 11,304 & 1,014 & 17,290 & 40,528 & 307 & 4,000 & 44,500 \\
\hline
\end{tabular}

Notes: This table presents descriptive statistics for the main variables in our final estimation sample. The unit of observation is firm-year. Share patents assigned divides the stock of patents that are assigned to affiliates by total patents stock. Share patents acquired divides the stock of acquired patents by total patents stock. 
Table 2. Organizational Structure, External Orientation, and Internal Research

\begin{tabular}{|c|c|c|c|c|c|c|c|c|c|c|c|c|}
\hline & (1) & (2) & (3) & (4) & (5) & (6) & (7) & (8) & (9) & (10) & $(11)$ & $(12)$ \\
\hline & & & \multicolumn{6}{|c|}{ External orientation } & \multicolumn{4}{|c|}{ Research } \\
\hline & $\begin{array}{c}\text { Average } \\
\text { sales }\end{array}$ & $\begin{array}{c}\text { Average } \\
\text { patents } \\
\text { Stock } \\
\end{array}$ & $\begin{array}{c}\text { Share of } \\
\text { patents } \\
\text { acquired }\end{array}$ & $\begin{array}{c}\text { Number of } \\
\text { targets }\end{array}$ & $\begin{array}{c}\text { Number of } \\
\text { targets over } \\
\text { sales (\$, } \\
\text { Billion) } \\
\end{array}$ & $\begin{array}{c}\% \text { of targets } \\
\text { absorbed }\end{array}$ & $\begin{array}{c}\text { Average } \\
\text { patents per } \\
\text { target }\end{array}$ & $\begin{array}{c}\% \text { of small } \\
\text { acquisitions }\end{array}$ & $\begin{array}{c}\text { Publications } \\
\text { stock }\end{array}$ & $\begin{array}{c}\text { Publications } \\
\text { stock over } \\
\text { sales }(\$, B) \\
\end{array}$ & $R \& D$ stock & $\begin{array}{c}R \& D \text { stock } \\
\text { over sales }\end{array}$ \\
\hline \multicolumn{13}{|c|}{ Level of decentralization } \\
\hline Centralized & 2,386 & 146.7 & 0.112 & 3.5 & 1.9 & 64.1 & 26.3 & 60.8 & 45.3 & 21.4 & 473.1 & 0.433 \\
\hline Hybrid & 4,283 & 298.8 & 0.288 & 10.8 & 3.0 & 41.9 & 50.0 & 43.2 & 100.2 & 10.5 & 842.2 & 0.290 \\
\hline Decentralized & 3,559 & 76.8 & 0.867 & 12.6 & 5.3 & 21.3 & 49.6 & 37.1 & 14.7 & 6.6 & 260.3 & 0.210 \\
\hline All & 3,410 & 174.3 & 0.421 & 10.6 & 3.1 & 35.9 & 46.7 & 43.3 & 57.6 & 12.2 & 553.2 & 0.302 \\
\hline
\end{tabular}

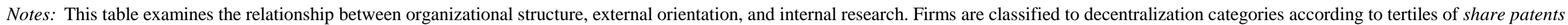
assigned. Column 4 counts the number of patenting targets acquired by our sample firms. Column 5 reports the percentage of targets that were absorbed. Targets are classified as absorbed if they cease to

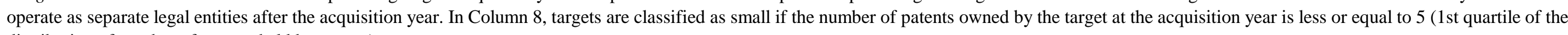
distribution of number of patents held by targets). 


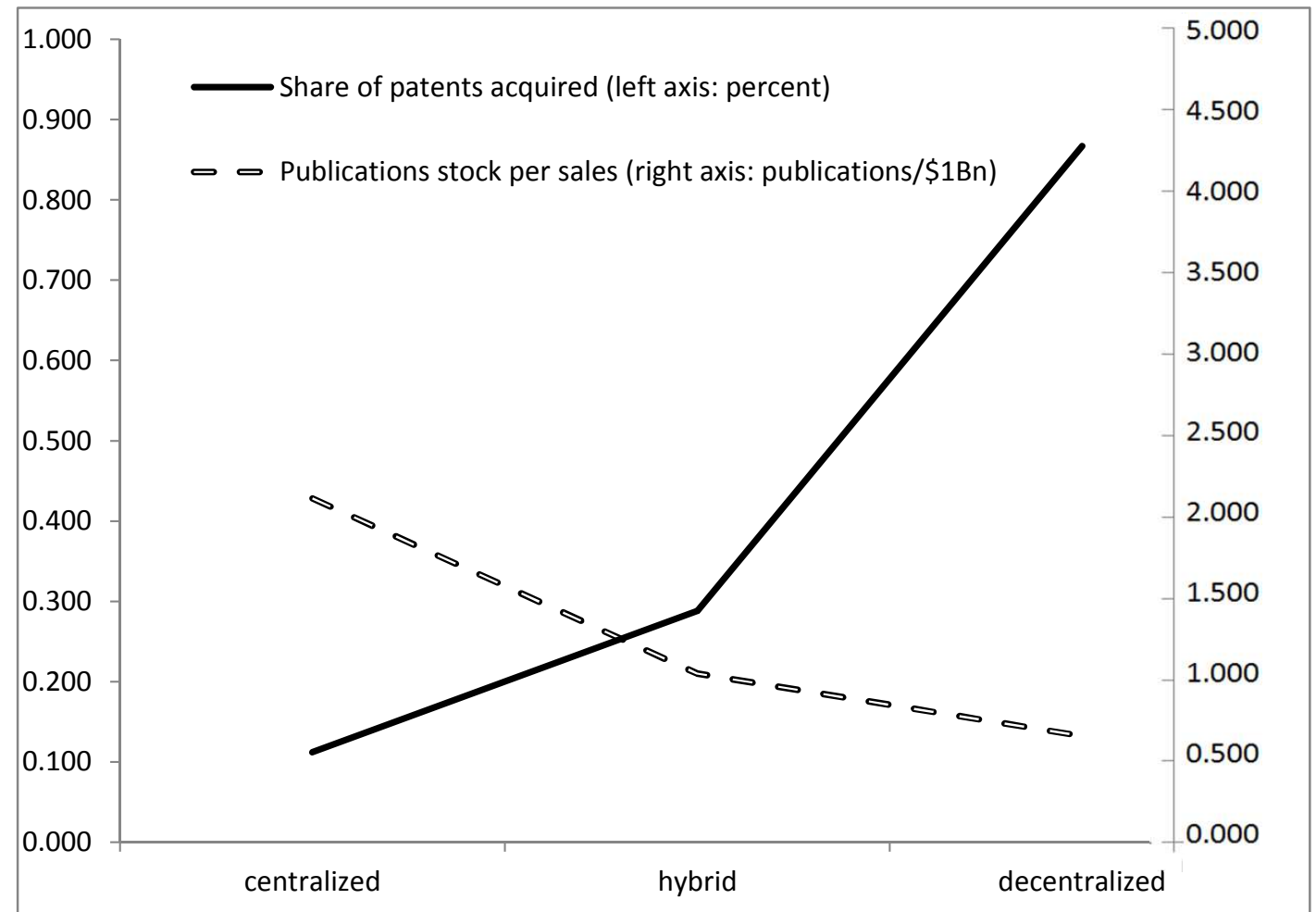

Figure 2: Measures for external orientation vs. internal research across tertiles of decentralization 
Table 3. How External Orientation and Internal Research are Related to Organizational Structure

\begin{tabular}{|c|c|c|c|c|c|c|c|c|c|c|c|c|c|}
\hline & (1) & $(2)$ & (3) & (4) & (5) & $(6)$ & (7) & $(8)$ & (9) & $(10)$ & $(11)$ & $(12)$ & (13) \\
\hline Dependent variable: & \multicolumn{2}{|c|}{$\begin{array}{c}\text { Share patents } \\
\text { acquired }\end{array}$} & \multicolumn{3}{|c|}{ Share targets absorbed } & \multicolumn{2}{|c|}{$\begin{array}{c}\text { Share of small } \\
\text { acquisitions }\end{array}$} & \multicolumn{2}{|c|}{$\begin{array}{c}\text { Publications } \\
\text { stock }\end{array}$} & \multicolumn{2}{|c|}{$R \& D$ stock } & \multicolumn{2}{|c|}{ Patent propensity } \\
\hline Dummy for Decentralized & $\begin{array}{c}0.75^{* *} \\
(0.03)\end{array}$ & $\begin{array}{c}0.75^{* *} \\
(0.03)\end{array}$ & $\begin{array}{c}-0.48^{* *} \\
(0.06)\end{array}$ & $\begin{array}{c}-0.47^{* *} \\
(0.05)\end{array}$ & $\begin{array}{c}-0.39 * * \\
(0.06)\end{array}$ & $\begin{array}{c}-0.27^{* *} \\
(0.05)\end{array}$ & $\begin{array}{c}-0.27^{* *} \\
(0.05)\end{array}$ & $\begin{array}{c}-0.48^{* *} \\
(0.14)\end{array}$ & $\begin{array}{c}-0.42^{* *} \\
(0.14)\end{array}$ & $\begin{array}{c}-0.73^{* *} \\
(0.16)\end{array}$ & $\begin{array}{c}-0.74 * * \\
(0.18)\end{array}$ & $\begin{array}{c}-0.23 * * \\
(0.09)\end{array}$ & $\begin{array}{l}-0.15 \\
(0.10)\end{array}$ \\
\hline Dummy for Hybrid & $\begin{array}{c}0.17 * * \\
(0.03)\end{array}$ & $\begin{array}{c}0.16^{* *} \\
(0.03)\end{array}$ & $\begin{array}{c}-0.23^{* *} \\
(0.05)\end{array}$ & $\begin{array}{c}-0.22 * * \\
(0.05)\end{array}$ & $\begin{array}{c}-0.16^{* *} \\
(0.05)\end{array}$ & $\begin{array}{c}-0.19 * * \\
(0.05)\end{array}$ & $\begin{array}{c}-0.19 * * \\
(0.05)\end{array}$ & $\begin{array}{c}0.06 \\
(0.15)\end{array}$ & $\begin{array}{c}0.09 \\
(0.15)\end{array}$ & $\begin{array}{c}0.02 \\
(0.16)\end{array}$ & $\begin{array}{c}0.02 \\
(0.16)\end{array}$ & $\begin{array}{c}0.00 \\
(0.10)\end{array}$ & $\begin{array}{c}0.03 \\
(0.10)\end{array}$ \\
\hline \multicolumn{14}{|l|}{ Dummy for Centralized (base) } \\
\hline Publications intensity & & $\begin{array}{c}-0.05^{*} \\
(0.28)\end{array}$ & & $\begin{array}{c}0.03^{* *} \\
(0.01)\end{array}$ & $\begin{array}{c}0.04^{* *} \\
(0.01)\end{array}$ & & $\begin{array}{l}-0.02 \\
(0.04)\end{array}$ & & & & & & \\
\hline Share patents acquired & & & & & & & & & $\begin{array}{l}-0.14 \\
(0.12)\end{array}$ & & $\begin{array}{c}0.03 \\
(0.15)\end{array}$ & & $\begin{array}{c}-0.20 * * \\
(0.09)\end{array}$ \\
\hline Share of small acquisitions & & & & & $\begin{array}{c}0.25^{* *} \\
(0.04)\end{array}$ & & & & & & & & \\
\hline $\ln (\text { Sales })_{\mathrm{t}-1}$ & $\begin{array}{c}0.01 \\
(0.01)\end{array}$ & $\begin{array}{c}0.01 \\
(0.01)\end{array}$ & $\begin{array}{l}-0.00 \\
(0.01)\end{array}$ & $\begin{array}{l}-0.01 \\
(0.01)\end{array}$ & $\begin{array}{l}-0.00 \\
(0.01)\end{array}$ & $\begin{array}{l}-0.01 \\
(0.01)\end{array}$ & $\begin{array}{l}-0.01 \\
(0.01)\end{array}$ & $\begin{array}{c}0.43^{* *} \\
(0.04)\end{array}$ & $\begin{array}{c}0.43^{* *} \\
(0.04)\end{array}$ & $\begin{array}{c}0.78^{* *} \\
(0.04)\end{array}$ & $\begin{array}{c}0.78^{* *} \\
(0.04)\end{array}$ & $\begin{array}{c}0.22 * * \\
(0.03)\end{array}$ & $\begin{array}{c}0.22 * * \\
(0.03)\end{array}$ \\
\hline $\ln (R \& D \text { Stock })_{\mathrm{t}-1}$ & & & & & & & & & & & & $\begin{array}{c}-0.72 * * \\
(0.03)\end{array}$ & $\begin{array}{c}-0.72^{* *} \\
(0.03)\end{array}$ \\
\hline Four-digit SIC dummies & Yes & Yes & Yes & Yes & Yes & Yes & Yes & Yes & Yes & Yes & Yes & Yes & Yes \\
\hline Year dummies & Yes & Yes & Yes & Yes & Yes & Yes & Yes & Yes & Yes & Yes & Yes & Yes & Yes \\
\hline R-squared & 0.60 & 0.60 & 0.33 & 0.33 & 0.37 & 0.23 & 0.24 & 0.51 & 0.51 & 0.71 & 0.71 & 0.80 & 0.80 \\
\hline Observations & 11,304 & 11,304 & 1,250 & 1,250 & 1,250 & 1,250 & 1,250 & 11,304 & 11,304 & 11,304 & 11,304 & 11,304 & 11,304 \\
\hline
\end{tabular}

Notes: This table examines the relationship between external orientation, internal research and organizational structure. Decentralization dummies are based tertiles of share patents assigned. The unit of observation is firm-year. Publications intensity is publications stock over sales. Share targets absorbed (Columns 3-5) divides the number of absorbed targets by the total number of targets. It classifies an acquisition as absorbed if it ceases to operate as a separate legal entity after the acquisition year. Share of small acquisitions (Columns 6 and 7) divides the number of small targets by total number of targets. Targets are classified as small if the number of patents owned by the target at the acquisition year is less or equal to 5 (1st quartile of the distribution of number of patents held by affiliates). Patent propensity (Columns 12 and 13) is the annual number of granted patents divided by R\&D stock. Standard errors are robust to arbitrary heteroskedasticity and allow for serial correlation through clustering by firms. **, * denote significance levels of 1 and 5 percent, respectively 
Table 4. Market Value Estimation: Contributions From Internal and External Research Across Varying Organizational Structure

Dependent variable: $\ln ($ Market Value )

\begin{tabular}{|c|c|c|c|c|c|c|c|c|c|}
\hline & $(1)$ & $(2)$ & (3) & $(4)$ & $(5)$ & $(6)$ & $(7)$ & $(8)$ & $(9)$ \\
\hline VARIABLES & & & & $\begin{array}{c}\text { Centraliz- } \\
\text { ed }\end{array}$ & Hybrid & $\begin{array}{l}\text { Decentral- } \\
\text { ized }\end{array}$ & $\begin{array}{c}\text { Centraliz- } \\
\text { ed }\end{array}$ & Hybrid & $\begin{array}{c}\text { Decentral- } \\
\text { ized }\end{array}$ \\
\hline $\ln (R \& D \text { Stock })_{t-1}$ & $\begin{array}{c}0.11^{* *} \\
(0.02)\end{array}$ & $\begin{array}{c}0.09 * * \\
(0.02)\end{array}$ & $\begin{array}{c}0.09 * * \\
(0.02)\end{array}$ & $\begin{array}{c}0.16^{* *} \\
(0.05)\end{array}$ & $\begin{array}{l}0.06 * \\
(0.03)\end{array}$ & $\begin{array}{c}0.07 * * \\
(0.03)\end{array}$ & $\begin{array}{c}0.13^{* *} \\
(0.05)\end{array}$ & $\begin{array}{l}0.04 \\
(0.03)\end{array}$ & $\begin{array}{l}0.05 \\
(0.03)\end{array}$ \\
\hline $\ln (\text { Patents Stock })_{\mathrm{t}-1}$ & & $\begin{array}{c}0.08 * * \\
(0.02)\end{array}$ & & & & & & & \\
\hline $\ln (\text { External Patents Stock })_{\mathrm{t}-1}$ & & & $\begin{array}{c}0.08 * * \\
(0.02)\end{array}$ & $\begin{array}{l}0.03 \\
(0.05)\end{array}$ & $\begin{array}{c}0.08 * * \\
(0.02)\end{array}$ & $\begin{array}{c}0.08 * * \\
(0.03)\end{array}$ & $\begin{array}{l}0.04 \\
(0.05)\end{array}$ & $\begin{array}{c}0.06^{* *} \\
(0.02)\end{array}$ & $\begin{array}{l}0.05 \\
(0.03)\end{array}$ \\
\hline $\ln (\text { Internal Patents Stock })_{\mathrm{t}-1}$ & & & $\begin{array}{c}0.07 * * \\
(0.02)\end{array}$ & $\begin{array}{l}0.09 * \\
(0.04)\end{array}$ & $\begin{array}{l}0.04 * \\
(0.02)\end{array}$ & $\begin{array}{c}0.08 * * \\
(0.03)\end{array}$ & $\begin{array}{l}0.09 * \\
(0.04)\end{array}$ & $\begin{array}{l}0.03 \\
(0.02)\end{array}$ & $\begin{array}{c}0.07 * * \\
(0.02)\end{array}$ \\
\hline $\ln (\text { Assets })_{t-1}$ & $\begin{array}{c}0.81^{* *} \\
(0.02)\end{array}$ & $\begin{array}{c}0.79 * * \\
(0.02)\end{array}$ & $\begin{array}{c}0.78 * * \\
(0.02)\end{array}$ & $\begin{array}{c}0.66 * * \\
(0.05)\end{array}$ & $\begin{array}{c}0.80 * * \\
(0.04)\end{array}$ & $\begin{array}{c}0.80 * * \\
(0.04)\end{array}$ & $\begin{array}{c}0.36 * * \\
(0.07)\end{array}$ & $\begin{array}{c}0.35 * * \\
(0.07)\end{array}$ & $\begin{array}{c}0.42 * * \\
(0.07)\end{array}$ \\
\hline $\ln (\text { Sales })_{t-1}$ & & & & & & & $\begin{array}{c}0.35 * * \\
(0.08)\end{array}$ & $\begin{array}{c}0.55 * * \\
(0.08)\end{array}$ & $\begin{array}{c}0.50 * * \\
(0.07)\end{array}$ \\
\hline Sales Growth & & & & & & & $\begin{array}{c}0.55^{* *} \\
(0.11)\end{array}$ & $\begin{array}{c}1.19 * * \\
(0.15)\end{array}$ & $\begin{array}{c}0.99 * * \\
(0.11)\end{array}$ \\
\hline Four-digit SIC dummies & Yes & Yes & Yes & Yes & Yes & Yes & Yes & Yes & Yes \\
\hline Year dummies & Yes & Yes & Yes & Yes & Yes & Yes & Yes & Yes & Yes \\
\hline R-squared & 0.83 & 0.83 & 0.83 & 0.83 & 0.85 & 0.88 & 0.85 & 0.88 & 0.89 \\
\hline Observations & 11,304 & 11,304 & 11,304 & 3,033 & 4,584 & 3,687 & 3,033 & 4,584 & 3,687 \\
\hline
\end{tabular}

Notes: This table examines the relationship between firm market value, R\&D, external orientation, and organizational structure. External patents are those obtained through acquisitions. Internal patents are those generated by internal divisions. Level of decentralization is based on tertiles of share patents assigned. Standard errors are robust to arbitrary heteroskedasticity and allow for serial correlation through clustering by firms. **, * denote significance levels of 1 and 5 percent, respectively. 
Table 5. Firm Market Value: Diversity and Size

\begin{tabular}{|c|c|c|c|c|c|c|c|c|c|c|c|c|}
\hline \multicolumn{13}{|c|}{ Dependent variable: $\ln ($ Market Value $)$} \\
\hline & $(1)$ & $(2)$ & (3) & $(4)$ & $(5)$ & $(6)$ & $(7)$ & $(8)$ & (9) & $(10)$ & $(11)$ & $(12)$ \\
\hline & \multicolumn{3}{|c|}{ High technological diversity } & \multicolumn{3}{|c|}{ Low technological diversity } & \multicolumn{3}{|c|}{ Above-median sales } & \multicolumn{3}{|c|}{ Below-median sales } \\
\hline & \multicolumn{3}{|c|}{ Share patents assigned } & \multicolumn{3}{|c|}{ Share patents assigned } & \multicolumn{3}{|c|}{ Share patents assigned } & \multicolumn{3}{|c|}{ Share patents assigned } \\
\hline VARIABLES & Low & Medium & High & Low & Medium & High & Low & Medium & High & Low & Medium & High \\
\hline $\ln (R \& D \text { Stock })_{t-1}$ & $\begin{array}{c}0.16 * \\
(0.05)\end{array}$ & $\begin{array}{c}0.05^{* *} \\
(0.02)\end{array}$ & $\begin{array}{l}-0.01 \\
(0.02)\end{array}$ & $\begin{array}{c}0.21^{* *} \\
(0.04)\end{array}$ & $\begin{array}{c}0.14^{* *} \\
(0.03)\end{array}$ & $\begin{array}{c}0.13^{* *} \\
(0.02)\end{array}$ & $\begin{array}{l}0.09 * \\
(0.04)\end{array}$ & $\begin{array}{c}0.05^{* *} \\
(0.02)\end{array}$ & $\begin{array}{l}0.01 \\
(0.02)\end{array}$ & $\begin{array}{c}0.33^{* *} \\
(0.04)\end{array}$ & $\begin{array}{c}0.08 * * \\
(0.03)\end{array}$ & $\begin{array}{c}0.13^{* *} \\
(0.03)\end{array}$ \\
\hline $\ln (\text { Patents Stock })_{\mathrm{t}-1}$ & & & & & & & & & & & & \\
\hline $\ln (\text { External Patents Stock })_{\mathrm{t}-1}$ & $\begin{array}{l}0.03 \\
(0.04)\end{array}$ & $\begin{array}{c}0.11^{* *} \\
(0.01)\end{array}$ & $\begin{array}{c}0.05^{* *} \\
(0.02)\end{array}$ & $\begin{array}{l}0.08 \\
(0.05)\end{array}$ & $\begin{array}{l}0.05 \\
(0.03)\end{array}$ & $\begin{array}{l}0.00 \\
(0.03)\end{array}$ & $\begin{array}{l}0.03 \\
(0.04)\end{array}$ & $\begin{array}{c}0.10^{* *} \\
(0.01)\end{array}$ & $\begin{array}{c}0.10^{* *} \\
(0.02)\end{array}$ & $\begin{array}{l}0.00 \\
(0.06)\end{array}$ & $\begin{array}{l}0.10 \\
(0.03)\end{array}$ & $\begin{array}{l}0.06 \\
(0.03)\end{array}$ \\
\hline $\ln (\text { Internal Patents Stock })_{\mathrm{t}-1}$ & $\begin{array}{l}-0.01 \\
(0.03)\end{array}$ & $\begin{array}{c}0.06^{* *} \\
(0.01)\end{array}$ & $\begin{array}{c}0.04 * \\
(0.02)\end{array}$ & $\begin{array}{c}0.11^{* *} \\
(0.04)\end{array}$ & $\begin{array}{l}-0.03 \\
(0.03)\end{array}$ & $\begin{array}{l}0.03 \\
(0.03)\end{array}$ & $\begin{array}{l}-0.03 \\
(0.03)\end{array}$ & $\begin{array}{c}0.06^{* *} \\
(0.01)\end{array}$ & $\begin{array}{c}0.10^{* *} \\
(0.01)\end{array}$ & $\begin{array}{c}0.17^{* *} \\
(0.03)\end{array}$ & $\begin{array}{l}0.00 \\
(0.03)\end{array}$ & $\begin{array}{l}0.06 \\
(0.03)\end{array}$ \\
\hline $\ln (\text { Assets })_{t-1}$ & $\begin{array}{c}0.80^{* *} \\
(0.06)\end{array}$ & $\begin{array}{c}0.80^{* *} \\
(0.03)\end{array}$ & $\begin{array}{c}0.78^{* *} \\
(0.05)\end{array}$ & $\begin{array}{c}0.67 * * \\
(0.05)\end{array}$ & $\begin{array}{c}0.57 * * \\
(0.04)\end{array}$ & $\begin{array}{c}0.69 * * \\
(0.03)\end{array}$ & $\begin{array}{c}0.52^{* *} \\
(0.06)\end{array}$ & $\begin{array}{c}0.70 * * \\
(0.02)\end{array}$ & $\begin{array}{c}0.70^{* *} \\
(0.04)\end{array}$ & $\begin{array}{c}0.40^{* *} \\
(0.05)\end{array}$ & $\begin{array}{c}0.68^{* *} \\
(0.05)\end{array}$ & $\begin{array}{c}0.67^{* *} \\
(0.04)\end{array}$ \\
\hline Sales Growth & $\begin{array}{c}0.32 * * \\
(0.09)\end{array}$ & $\begin{array}{c}1.26^{* *} \\
(0.13)\end{array}$ & $\begin{array}{c}0.82^{* *} \\
(0.07)\end{array}$ & $\begin{array}{c}0.50 * * \\
(0.07)\end{array}$ & $\begin{array}{c}0.81^{* *} \\
(0.16)\end{array}$ & $\begin{array}{c}0.58^{* *} \\
(0.09)\end{array}$ & $\begin{array}{c}0.22^{* *} \\
(0.07)\end{array}$ & $\begin{array}{c}1.01^{* *} \\
(0.11)\end{array}$ & $\begin{array}{c}0.60 * * \\
(0.06)\end{array}$ & $\begin{array}{c}0.43^{* *} \\
(0.07)\end{array}$ & $\begin{array}{c}1.04 * * \\
(0.15)\end{array}$ & $\begin{array}{c}0.75^{* *} \\
(0.12)\end{array}$ \\
\hline Four-digit SIC dummies & Yes & Yes & Yes & Yes & Yes & Yes & Yes & Yes & Yes & Yes & Yes & Yes \\
\hline Year dummies & Yes & Yes & Yes & Yes & Yes & Yes & Yes & Yes & Yes & Yes & Yes & Yes \\
\hline R-squared & 0.88 & 0.86 & 0.91 & 0.76 & 0.81 & 0.86 & 0.82 & 0.81 & 0.85 & 0.61 & 0.63 & 0.66 \\
\hline
\end{tabular}

Notes: This table examines how the market value results vary by firm technological diversity and size. Firms are classified as having low or high technological diversity according to the sample median value of the number of three-digit technology classes the firm patents in. Level of decentralization is based on tertiles of share patents assigned. Standard errors are robust to arbitrary heteroskedasticity. **, * denote significance levels of 1 and 5 percent, respectively. 